\title{
Varying universal health coverage policy implementation states: exploring the process and lessons learned from a national health insurance pilot site
}

\author{
Janet Michel' ${ }^{1}$ Nthabiseng Mohlakoana², Till Bärnighausen³, Fabrizio Tediosi', Di Mclntyre ${ }^{4}$, Hans T A Bressers ${ }^{5}$, Marcel \\ Tanner ${ }^{1}$, David Evans ${ }^{6}$ \\ 1 Swiss Tropical and Public Health Institute (Swiss TPH), Basel, Switzerland; University of Basel, Basel, Switzerland, ${ }^{2}$ Department of Governance and \\ Technology for Sustainability, University of Twente, Twente, Netherlands, ${ }^{3}$ Institute of Public Health, University of Heidelberg, Heidelberg, Germany; \\ Harvard T. H. Chan School of Public Health, Boston, Massachusetts, USA, ${ }^{4}$ Health Economics Unit, University of Cape Town, Cape Town, South Africa, \\ ${ }^{5}$ Policy Studies and Environmental Policy, University of Twente, Twente, Netherlands, ${ }^{6}$ World Bank Health Economist, Geneva, Switzerland \\ Keywords: policy implementation, varying implementation states, lessons learned, why \\ https://doi.org/10.29392/001c.12857
}

\section{Journal of Global Health Reports}

Vol. 4, 2020

\begin{abstract}
Background
Worldwide efforts have increased to understand what works in policy implementation, for whom and under what circumstances (context) are health policies useful and effective. All countries are striving towards Universal Health Coverage (UHC). Reforms are being implemented to ensure no-one is left behind.
\end{abstract}

\begin{abstract}
Methods
We draw on our experiences of tracking implementation of policies aimed at achieving UHC in a national health insurance (NHI) pilot district (universal coverage in Tanzania and South Africa). Policies aimed at achieving UHC were tracked from 2011-2015 to understand why there are varying UHC policy implementation states and outcomes among facilities in the same district?
\end{abstract}

\begin{abstract}
Results
Lessons learned in the process include: i) to adopt or adapt policy is a process - actors at the front-line seem to engage with policy, carry out a policy-context audit, try to engage with superiors if there are discrepancies between policy and context and eventually take a decision to adopt or adapt policy; ii) local facility contexts matter and vary - decision to implement policy is influenced by the conditions on the ground, hence implementation states can vary from one facility to the other despite being in the same district; iii) implementation states range from full policy adoption and implementation, policy adaptation and partial implementation, delayed implementation to non-implementation; iv) a resource audit before policy is implemented could go a long way in reducing policy-practice gaps; and v) Policy implementation states are dynamic subject to change - for example, when equipment breaks down and is not replaced immediately.
\end{abstract}

\section{Conclusion}

There seems to be inherent respect among implementing actors, for the department of health and people above them. They are however concerned with the fact that they are removed from the ground, could have lost touch with realities on the ground, hence the policy directives sent from the top, are often not congruent with ground conditions. Actors revealed how they engage with the policy, assess what they are being asked to do and compare that with the existing resources. To adopt or adapt policy in a UHC context: there seems to be a series of steps actors take.

World-wide efforts have increased to understand what works in policy implementation, for whom and under what circumstances (context) are health policies useful and effective. ${ }^{1-3}$ Volatility, uncertainty, complexity and ambiguous (VUCA) are terms that have been associated with the current climate in all sectors including the economy, and the health system has not been spared. ${ }^{4}$ Health systems in Southern Africa are already strained amid pervasive poverty, meagre human, infrastructural, material and monetary resources. ${ }^{5}$

South Africa transitioned to full democracy in 1994 and fundamental societal and health system reforms were intro- 
duced. The government adopted primary health care as a vehicle to deliver health the first time, then in $1994 .{ }^{6}$ Overtime many PHC initiatives have been implemented including the establishment of nine provincial departments and elimination of race and gender inequalities. New infrastructure has been built to make health care more accessible including services to cope with burden of diseases particularly the HIV and TB epidemics. ${ }^{6}$

Piloting National health Insurance and reengineering of PHC began in 2011, putting South Africa on a new journey. ${ }^{7}$ Multiple challenges are being faced in PHC among others weak management and lack of leadership to oversee the implementation of polies that are generally viewed as good. ${ }^{8-11}$ Some view the district based system as one of the most fundamental post 1994 initiatives which would facilitate equity and responsiveness. ${ }^{6}$ Lack of decision making power, inefficiencies, infrastructure and supply chain challenges were revealed as affecting new interventions. ${ }^{6,12}$

All countries are moving towards UHC-making sure that all citizens get high quality services when they need them, without being pushed into poverty. ${ }^{13,14}$ Public policy or government policy is defined as whatever governments choose to do or not to do. ${ }^{15}$ Policy implementation refers to the mechanisms, resources, and relationships that link policies to program action. ${ }^{16}$ Many barriers can inhibit policy implementation even when there is widespread agreement about the merits of an intervention. ${ }^{17,18}$ The barriers may present themselves at many levels of the system and failure of policy can be caused by poor execution, a poorly developed policy or just having no luck. Information or policy that is ambiguous can overwhelm policy implementers and resource challenges impede implementation. ${ }^{19}$ In low resource settings, challenges are multiple and range from leadership, health system challenges to poor communication and adoption of policy. ${ }^{20}$ The South African public health system currently suffers from the implementation gap between sound policy frameworks and the delivery of improvements they seek. ${ }^{10}$ The study aimed at tracking NHI policy implementation process through the engagement of policy makers and policy implementers in order to explore, identify and describe why and how policy-practice discrepancies come about in UHC context. Several research questions were explored guided by an interview guide.

\section{METHODS}

\section{RESEARCH QUESTION}

"How and why do discrepancies between policy and practice
come about from your (actors) current policy implementa-
tion experience? Identify and describe an instance in the
course of duty where you (actor) or colleagues deviated
from policy."

\section{RESEARCH CONTEXT}

We reflect on our experiences of tracking UHC policy implementation in one NHI pilot district in South Africa. Universal Health Coverage in Tanzania and South Africa (UNITAS) engaged with actors that were involved in UHC policy implementation from 2011-2015.

An exploratory, qualitative case study design utilizing a theory of change, was followed to explore universal health coverage policy implementation experiences. TOC is a theory of how and why initiatives work. ${ }^{21}$ TOC is a tool that describes assumptions actors have, explains steps and activities they take to achieve goals and connections between these activities and the policy outcome. ${ }^{21}$ Thus, theory of change made it possible for actors at facility, sub-district, district, and principal levels to reflect on their experiences of policy implementation including perceptions and assumptions they held. In-depth face to face interviews, utilizing a TOC interview guide were held between 2011-2015 (three phases: 2011-2012- contextual mapping; 2013-2014-phase 1 and 2015- phase 2). Key informants $(\mathrm{n}=71)$ ranged from provincial actors (policy makers) district, subdistrict and PHC facility actors (policy implementers). Transcripts were coded in MAXQDA2018. An iterative, inductive and deductive data analysis approach guided by Contextual Interaction theory was utilized.

\section{RESEARCH SETTING AND SAMPLING}

Ten pilot districts were identified by the department of health and selected NHI pilot sites. The health department selected these sites based on poor performance on key health indicators like high maternal and child mortality rates. $^{22}$ UNITAS purposively selected three out the ten selected NHI pilot districts in South Africa. A case study design, an empirical inquiry that investigates phenomenon in real life context was used for this research. ${ }^{23}$ This study is situated in only one of the three districts, district X (name withheld for anonymity reasons). The case was the district (X), conveniently selected as the only NHI pilot district in that province at the time. Managerial support and willingness to participate in the study also guided site selection.

\section{DATA ANALYSIS AND MEASURES TO ENSURE TRUSTWORTHINESS}

An iterative, inductive and deductive approach guided by CIT theory was utilized. Transcripts were coded with the aid of MAXQDA2018. To evaluate rigour, criteria for trustworthiness were used namely transferability, dependability, confirmability and credibility. ${ }^{24}$ We describe the data collection process in detail and how two researcher kept reflective journals to ensure dependability. Debriefing after interviews was done daily in the field. The two researchers further analysed the data independently before reaching consensus under the supervision of an experienced qualitative researcher. To ensure confirmability findings were discussed with supervisors and co-authors experienced in the field, and their responses were incorporated. Participants, context and process of analysis have been described in detail to ensure transferability. ${ }^{24}$ We achieved data saturation $^{25}$ and data source triangulation, through interviewing actors from different levels of the health system

\section{RESULTS}

Individually and collectively reflecting on our experiences and insights from interviews held with actors involved in UHC policy implementation, we have compiled a set of 
Table 1. Overview of key informants, research phase, role and where they worked (health system level)

\begin{tabular}{|c|c|c|c|c|c|}
\hline $\begin{array}{l}\text { Health } \\
\text { System } \\
\text { Level }\end{array}$ & Role & $\begin{array}{l}\text { Contextual } \\
\text { mapping }\end{array}$ & $\begin{array}{l}\text { Round } \\
1\end{array}$ & $\begin{array}{l}\text { Round } \\
2\end{array}$ & Total \\
\hline Provincial & Policy maker -making sure $\mathrm{NHI}$ policies are carried out & 1 & 1 & 1 & 3 \\
\hline District & $\begin{array}{l}\text { Policy implementers ranging from district manager, } \\
\text { programme managers, district clinical specialist team, } \\
\text { Emergency rescue service manager and PHC supervisors } \\
\text { with policy implementation responsibilities including the } \\
\text { PHC supervision manual }\end{array}$ & 1 & 5 & 4 & 10 \\
\hline $\begin{array}{l}\text { Sub- } \\
\text { district }\end{array}$ & $\begin{array}{l}\text { Policy implementers at subdistrict level ranging from CEOs } \\
\text { managers, nurses and doctors implementing policies aimed } \\
\text { at UHC as well as providing direct patient care }\end{array}$ & 3 & 12 & 8 & 23 \\
\hline $\begin{array}{l}\text { PHC } \\
\text { facility }\end{array}$ & $\begin{array}{l}\text { Policy implementers including operational managers and } \\
\text { staff in PHC facilities implementing policies aimed at UHC as } \\
\text { well as providing direct patient care }\end{array}$ & - & 19 & 16 & 35 \\
\hline Total & & 5 & 37 & 29 & 71 \\
\hline
\end{tabular}

CEO - chief executive officer, NHI - national health insurance, PHC - primary health care UHC - universal health coverage

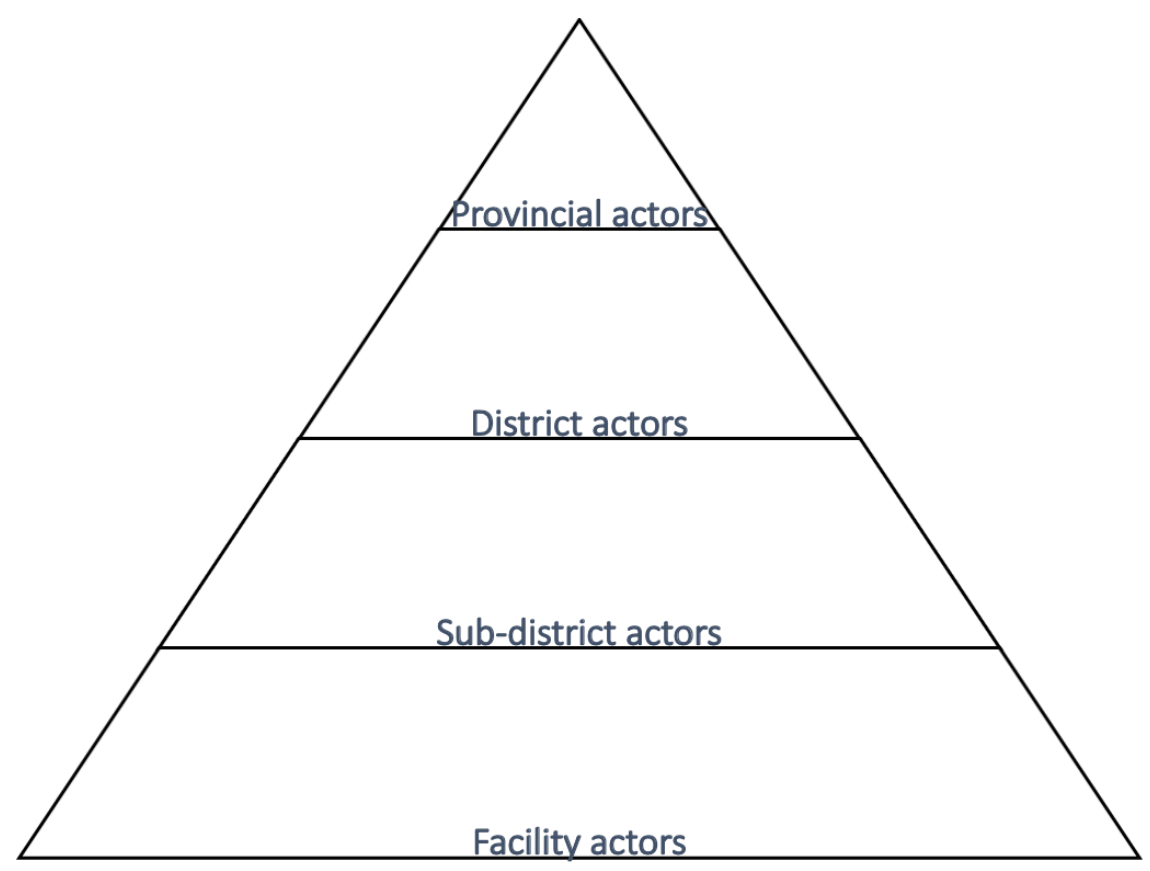

Figure 1. Level of health system actors represented

lessons learned. Each lesson is described below with supportive quotes and examples from the field. We observed through-out our study that there seems to be inherent respect among implementing actors for the department of health and people above them who have authority. They are however concerned with the fact that they are removed from the ground, often have lost touch with realities on the ground, hence the policy directives sent from the top are not always congruent with ground conditions. ${ }^{26,27}$ To that effect, the actors revealed how they engage with the policy, assess what they are being asked to do, compare that with the existing resources, personnel, material and infrastruc- tural, and if these allow- a policy context fit is proven, the policy is adopted fully. If on the other hand, a challenge is identified, depending on the resources available- a policy context alignment is done, resulting in adapted policy, delayed implementation or non-implementation. To adopt or adapt policy in a UHC context there seems to be a series of steps actors to take as explained below 


\section{POLICY ADOPTION OR ADAPTATION: THE PROCESS}

\section{STEP 1: POLICY CONTEXT AUDIT - ACTORS ENGAGE WITH TOP DOWN POLICY DIRECTIVES UPON RECEIVING THEM}

Facility actors do engage with the policies they receive. They do a policy-context audit in which they assess what the policy is saying, how it should be implemented and then equate that with existing and available resources. When resources and capacity are available, they are motivated to implement policy and did so during the research period.

\section{STEP 2: ENGAGEMENT WITH SUPERVISORS}

If on the other hand, they find incongruencies e.g. the infrastructure does not allow or there is a staff shortage, they tried to engage with the superiors and authorities to meet policy requirements. There is however no clear person to contact and negotiate policy adaptation when needed. Front-line actors tried to engage with their primary health care (PHC) supervisors. They wrote motivational letters which were usually futile as they were hardly if at all responded to. Poor quality of care in the public sector has been attributed to poor stewardship and weak leadership ${ }^{28}$ in all sectors in South Africa. ${ }^{29}$ These endless motivational letters were for equipment, material or staff that they needed in order to implement dictated policy. Non- response from above in turn affected their motivation. They revealed the following;

"And when we report to our PHC supervisors, they said no they can't do anything. it is beyond them." -facility actor round 2 .

"The shortage of staff is beyond our operational manager and PHC supervisor's control. Sometimes, our manager motivates for posts and they say there is no money. That is the problem." - facility actor round 1.

Some initiatives like the one register that was meant to streamline more than 17 registers the clinics had to contend with, were communicated to implementing actors as coming but never saw the light of day during the research period. Frontline actors are often not updated.

"That one register. It was supposed to have been implemented I think three months ago. But it never started, excuse me, never happened and our bosses never communicated." -subdistrict actor round 2

"And I do not know what is delaying the process of replacing the staff that is gone. I communicate with the PHC supervisor and I plead with him to please come so that he can see what I am talking about but he has not come."-facility actor round 2

\section{STEP 3: DECISION MAKING AND IMPLEMENTATION STATES}

Depending on the outcome of policy-context audit, engagement with supervisors, actors are then left to take a decision. According to Lipsky $1980^{30}$ implementing actors implement policies according to what they think is best. This is not a result of defying authority or going against the rules set by those at the top, instead it is a way in which actors at the bottom cope with the implementation of policies that are otherwise out of their scope because of the way they are planned. According to Bressers, implementation can be differentiated whether the implementation is adequate to satisfy policy aims. ${ }^{31}$ Decisions taken can be any of the following;

\section{POTENTIAL OUTCOME 1: FULL POLICY ADOPTION AND IMPLEMENTATION}

One policy initiative being implemented is the ideal clinic, which recommends patients to be seen in three streams, namely chronic illness, maternal, new born, child and women`s health and minor ailments. Facilities that got new NHI buildings and the needed staff, implemented this approach and were very happy with results as revealed below;
"We got more staff last year and a new NHI building. yes, from last year and you can see patients don't wait too long anymore. So, we could implement the three streams approach and the waiting times have improved greatly." -facility actor round 2

\section{POTENTIAL OUTCOME 2: POLICY ADAPTATION AND PARTIAL IMPLEMENTATION}

Some of the facilities revealed how they adapted policy to meet the situation on the ground. For example, a threestream approach requires at least 3 PHC nurses and some facilities only had two and so had to combined some streams, adapting policy as revealed below

"At the moment, we are not fully implementing those,
but because, personally, I didn't have staff. There are
only two Sisters, and the streams approach needs three
or four Sisters to cater for leave and absences." -facility
actor round 1

\section{POTENTIAL OUTCOME 3: DELAYED IMPLEMENTATION}

The three streams policy was viewed by all facility actors as good and relevant. The staff and infrastructural challenges led to different implementation outcomes based on each facility context. Many decided to delay the implementation until a conducive time as revealed below

"Staffing. We have very few staff. Right, because if they want this three-stream program kind of thing, we need about three registered nurses, each per program. We only have got one registered nurse. I cannot implement that." -facility actor round 1

"The structure of the clinic does not allow. According to ideal clinic the way we do things needs to change to make three streams; children to be in one area and the chronic patients to be in another area and so on. Then when we looked at the structure of the clinic, it does not allow for that, but we were told to do those things but unfortunately, we cannot implement them." -facility actor round 2

* "The policy says there should be an integration whereby all the chronic patients should be treated under one roof-not discriminating especially the clients that are for ARV's, and TB's. You know the communicable and 


\section{Step 1: Policy-context audit}
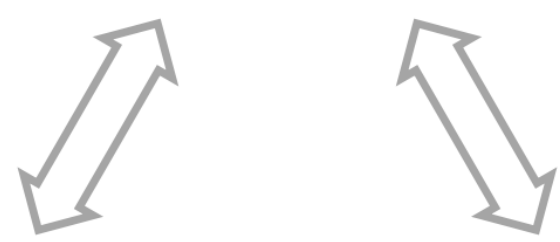

\section{Step 3: Decision making and Implementation states}

Figure 2. Diagrammatic summary of the process

non-communicable diseases. To be honest to you for us right now we are not implementing that because of the infrastructural challenge." -*facility actor round 2

"At the moment, we are not fully implementing those, but because, personally, I didn't have staff. There are only two Sisters, and the streams need three or four Sisters."-facility actor round 1

"But we have not started because when we were about to start or initiate that particular program (Medipost), we identified lots of things that need to be in place before we could start on that particular day. First of all, the data capturer, because we are supposed to capture data every day then file all those things and we found that we do not have filing cabinets." -facility actor round 2

\section{POTENTIAL OUTCOME 4: NON-IMPLEMENTATION}

Some facility actors, after policy-context audit concluded that there was a policy context misfit or irrelevance- and did not even bother to implement the policy-saw it as does not work here and never got started at all $^{31}$ as revealed below;

"Especially with that one stop shop they are proposing, I am saying that one stop shop is not going to function at all. Not with us, maybe somewhere it will work... because you can't keep all these registers here. You can't see an antenatal care (ANC) client after seeing a $T B$ client, after seeing a client on prevention of mother to child transmission regime. The queue will just stand." -facility actor round 1

\section{DYNAMIC STATES OF POLICY IMPLEMENTATION}

Actors also revealed that policy implementation is not static but a dynamic process. An institution can be policy compliant one day and may find themselves non-compliant the next day e.g. if a staff member trained to offer a particular service like ART falls sick or resigns. According to Kotzebue the place affects motivation, perception and capacities of implementing actors and the outcomes of implementation processes. During implementation characteristics of the place can change affecting implementation. ${ }^{32}$ Another dynamic state is transition. Actors found themselves in a state we termed transition state, when the old policy or way of doing things has not really been phased out and the new has not taken root. Such transition states need to be planned for**

\footnotetext{
*"The infection control practitioners with the initial lot do training when they come into our facility, they train the staff but when there is staff movement and resignations, we lose the trained staff. So, if you are getting two new staff every day you do not expect us to go and train two new people every day." -*subdistrict actor round 2
}

"The change that has come with NHI in this facility is that when I came here there was no pharmacy assistant. Now there is pharmacy assistant who orders the medication. But also, we only have one, now she is gone for maternity leave and there is nobody relieving her. We are now back to having a nurse to fit in her place. She does not have a relief; the duties fall back onto the nurses. So, okay it is implemented but it is not fully implemented." -facility actor round 2

\section{GAP-WHO TO CONTACT AFTER POLICY-CONTEXT AUDIT?}

The absence of a clear person at district level to engage with 
when the actors find a policy-context misfit, a discrepancy between policy demands and the resource realities on the ground is fuelling policy-practice gaps. PHC supervisors are contacted but they often lack power and authority to solve problems. Attempts to get help yields nothing as they are often met with non-responsiveness. It is this interaction process that we found critical to policy implementation in our study. This non-responsiveness accompanied by policing supervision creates another set of responses from frontline actors further fuelling policy practice gap above and beyond the resources, process and system challenges. The actors revealed how in such cases they are then forced to delay or adapt policy implementation

\begin{abstract}
"They have prescribed, they say you may not do open reductions and fixations and that because it is not in the district package of service. But every second patient that comes out of a car crash needs that. So that has an impact on us as we do not get funds for that but it has to be done, because I can see the need." -subdistrict actor round 2
\end{abstract}

"We are told to improve our figures (statistics), go out to the community and tell them about circumcision....because we are short staffed as it is, one of the sisters resigned and, she's still not replaced and then Sister ... our operational manager passed away, so that means we are two professional nurses less in the team. Go to the community and tell them about circumcision when we short staffed, who is going to stay here and run the clinic when we go out? You see that's a problem?"-facility actor round 2

"Because it is not easy to implement all these new things-the new programs if we have got limited resources. Medipost... we are supposed to be implementing these pick-up points in the community. All of us realise that it is going to be of use to us because it is going to decongest the clinic, but at times we do not know how we are to implement it without a vehicle." -facility actor round 2

See figure 3 below;

\section{LESSONS LEARNED}

1. To adopt or adapt policy is a process. Actors at the frontline seem to engage with policy, carry out a policy-context audit, try to engage with superiors if there are discrepancies between policy and context and eventually take a decision to adopt or adapt policy. 2) Local context matters and varies. Decision to implement policy is influenced by the conditions on the ground, ${ }^{20}$ hence this can vary from one facility to the other despite being in the same district. 3) Implementation states range from full policy adoption and implementation, to policy adaptation and partial implementation, delayed implementation or non-implementation when policy is deemed not relevant to context or resources are not available. 4) A resource audit before policy is implemented could go a long way in reducing policy-practice gaps. 5) Policy implementation states are dynamic. A facility that is policy compliant today may find themselves non-compliant the next day e.g. if a staff member trained to offer a particular service like ART falls sick or resigns or equipment break down and is not replaced immediately.

\section{LIMITATIONS AND STRENGTHS}

Methodologically theory of change allowed us to explore the implementing experiences of both policy makers and policy implementers giving us a broader picture of how change happens in a UHC context. We also engaged with actors working in different health system levels, giving us an opportunity to triangulate and get a rounded picture. The study being qualitative in nature means that our findings though transferable, might not reflect what happens in other contexts.

\section{Box 1. Key messages}

1. Policy implementation takes time. Between the point of policy communication and full compliance, many issues may arise and patient care has to continue either way. Acknowledging and planning for transition states could ensure positive patient outcomes.

2. Policy implementation is dynamic. Being compliant at one stage does not guarantee continued compliance for example, the training of cleaning staff in infection control principles is subject to change the moment the staff resigns

3. Local context matters and varies. Decision to implement policy is influenced by the conditions on the ground; hence this can vary from one facility to the other despite being in the same district. A resource audit before policy is implemented could go a long way in reducing policypractice gaps.

\section{CONCLUSIONS}

Ideally, policy implementers should be involved in policy development to ensure buy in and policy relevance. Actors revealed that NHI policies were developed at the top and communicated to the frontline. In line with our findings top down approaches have been found to inhibit ownership and not reflect local contexts. ${ }^{26,33}$ Our engagement with both policy makers (province level) and policy implementers revealed that the process to adopt or adapt policy, seems to be complicated ${ }^{34}$ among others by a structural gap. There seems to be a no identified official or office to contact, in the event actors at the frontline have challenges with policy or see a policy-context misfit. Policy makers seem to assume that when policies are communicated down to the implementing actors, the actors immediately understand, know what to do and that conditions are conducive. ${ }^{35,36}$ This was revealed not to be the case; hence we recommend having such a transitional authority or office to smoothen policy implementation. 


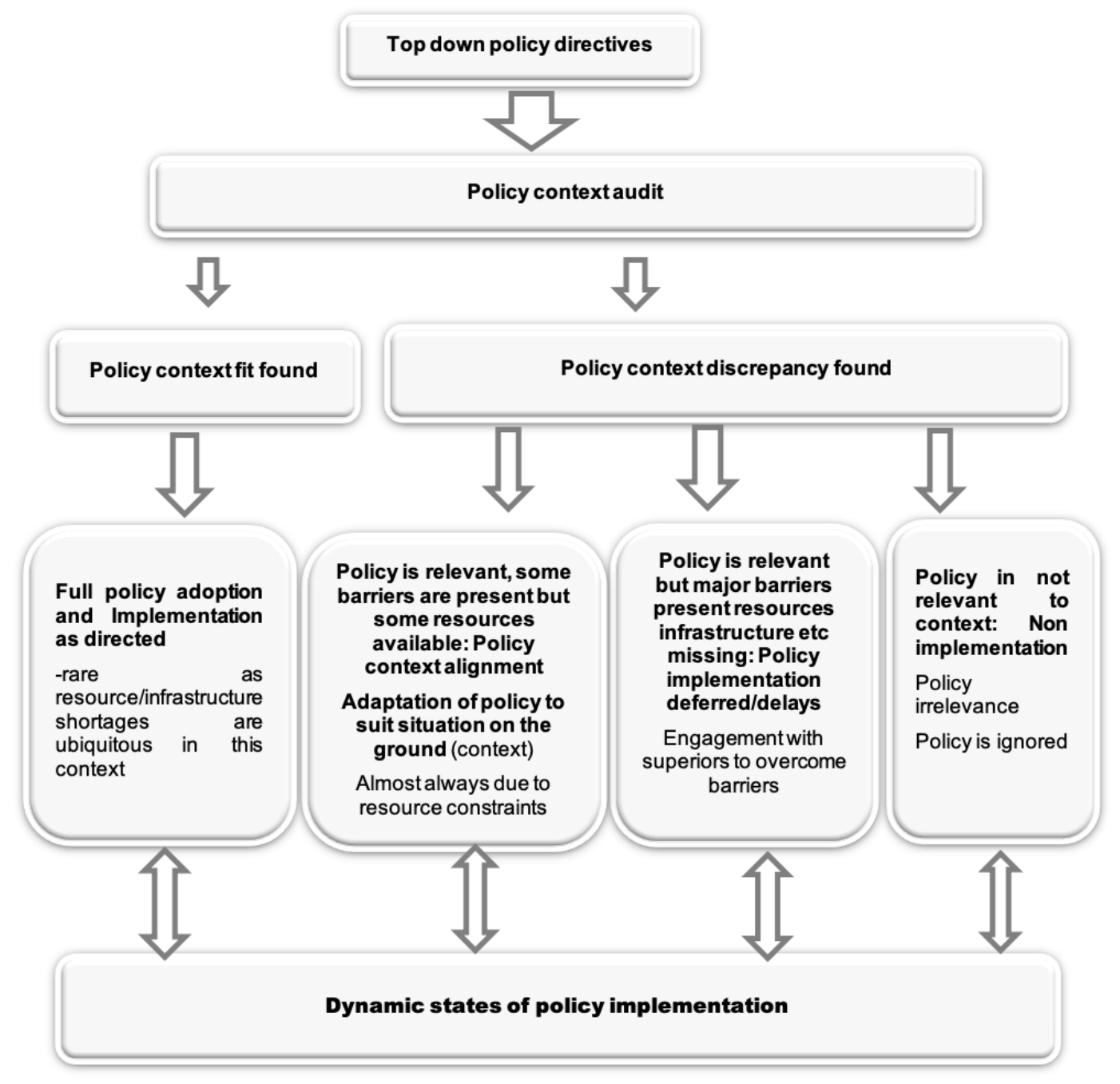

Figure 3. How implementing actors proceed and why the varying implementation states in facilities

Our engagement also revealed that compliance with policy implementation is dynamic concurring with findings elsewhere. ${ }^{32}$ Being compliant at one stage does not guarantee continued compliance for example, the training of cleaning staff in infection control principles is subject to change the moment the staff resigns or the three-stream approach is only manageable as long as the clinic has at least three PHC nurses. The moment one staff member goes on leave or falls sick, the facility actors are immediately forced to adapt policy. Planning for staff leave and relief of special cadres and staff categories particularly the new cadres, pharmacy assistants could go a long way in ensuring facilities remain compliant. Policy implementation takes time. ${ }^{34}$ Between the point of policy communication and full compliance, many issues may arise and patient care has to continue either way. Acknowledging and planning for transition states could ensure positive patient outcomes. The same authority that attends to policy-context challenges could be tasked with assisting facilities deal with transition states like staff establishments dictated from above despite the patient needs on the ground.
Acknowledgements: We thank UNITAS project team including Prof Lucy Gilson, Professor Jane Goudge, DR Bronwyn Harris, Kafayat Oboirien, Dr Natsayi Chimbindi, Marsha Orgill, Maylene Shung King and Mr Ermin Erasmus. Special thanks to Professor Brigit Obrist for supporting me through-out data analysis. We also thank all department of health staff who took part in the study.

Ethics approval: The study complied fully with the Helsinki Declaration principles as amended in Tokyo, Venice, Hongkong and South Africa. Full ethical approval REF BEF 197/13 was obtained by UNITAS from the University of KwaZulu-Natal Biomedical Research Ethics Committee. Gatekeeper permission was granted by KZN Provincial Health Department REF HRM4/2 granted. Individual informed written consent was granted by all actors who participated in the study.

Availability of data: Material and data from this research cannot be publicly provided and shared due to our ethical obligations to protect anonymity of participants. As stipulated in the participants "informed consent," data access is limited to members of UNITAS research team only. For fur- 
ther information, contact corresponding author.

Funding: The European Commission`s Seventh Framework Programme (FP7-CP-FP-SICA, grant agreement number 261349) funded this study.

Authorship contributions: JM contributed to initial paper concept and wrote first draft NM, TB, FT, DM, HTAB, MT and DE commented and contributed to subsequent drafts.

Competing interest: The author completed the Unified Competing Interest form at www.icmje.org/coi disclo- sure.pdf (available upon request from the corresponding author), and declare no conflicts of interest.

\section{Correspondence to:}

Janet Michel

PhD student in Epidemiology, Health Systems and Policy Unit

Swiss TPH, Basel, Switzerland

University of Basel, Switzerland

janetmichel71@gmail.com 


\section{REFERENCES}

1. Peterson S. Assessing the scale-up of child survival interventions. The Lancet. 2010;375(9714):530-531. $\underline{\mathrm{d}}$ oi:10.1016/s0140-6736(09)62193-0

2. Reynolds J, DiLiberto D, Mangham-Jefferies L, et al. The practice of 'doing' evaluation: Lessons learned from nine complex intervention trials in action. Implementation Sci. 2014;9(1). doi:10.1186/1748-590 $\underline{8-9-75}$

3. Kruk ME, Yamey G, Angell SY, et al. Transforming Global Health by Improving the Science of Scale-Up. PLoS Biol. 2016;14(3):e1002360. doi:10.1371/journa 1.pbio. 1002360

4. Halamka J. Volatility, Uncertainty, Complexity and Ambiguity | Healthcare Finance News. Health Care Finance. 2011. https://www.healthcarefinancenews.co $\mathrm{m} / \mathrm{blog} /$ volatility-uncertainty-complexity-and-ambig uity. Accessed July 19, 2019.

5. van Rensburg HC. South Africa's protracted struggle for equal distribution and equitable access still not there. Hum Resour Health. 2014;12(1). doi:1 $\underline{0.1186 / 1478-4491-12-26}$

6. Harrison D. An Overview of Health and Health care in South Africa 1994 - 2010: Priorities. Progress and Prospects for New Gains. 2010:40.

7. Department of Health. National-Health-Insurancefor-South-Africa-White-Paper.Pdf .; 2015. https://ww w.health-e.org.za/wp-content/uploads/2015/12/Natio nal-Health-Insurance-for-South-Africa-White-Pape r.pdf. Accessed September 20, 2018.

8. Leader. 9 major problems facing South Africa - and how to fix them | Leader.co.za 2011. http://www.leade r.co.za/article.aspx? $\mathrm{s}=1 \& \mathrm{f}=1 \& \mathrm{a}=2893$. Accessed September 20, 2018.

9. Berwick D, Hiatt H, Janeway P, Smith R. An ethical code for everybody in health care. BMJ.

1997;315(7123):1633-1634. doi:10.1136/bmj.315.712 $\underline{3.1633}$

10. Ellokor S, Gilson L. The DIAHLS Project: District Innovation and Action Learning for Health System Development in 2nd HSR Symposium,2012. Beijing; 2012.

11. Gilson L. Management and health care reform in sub-Saharan Africa. Social Science \& Medicine. 1995;40(5):695-710. doi:10.1016/0277-9536(95)8001 3-a
12. Barroni P. Padarath A. South African Health Review 2017. 2017.

13. Brearly L, Marten R, O’Connell T. Universal health coverage: Commitment to close the gap. 2013.

14. McIntyre D. Confused about the NHI? One of SA's leading health economists breaks it down for you. Bhekisisa. 2020. https://bhekisisa.org/opinion/2020-0 1-28-how-national-health-insurance-will-change-ho w-healthcare-managed-south-africa-di-mcintyre. Accessed May 11, 2020.

15. Burke K, Morris K, McGarrigle L. Centre for Effective Services (Dublin I. An Introductory Guide to Implementation: Terms, Concepts and Frameworks. Dublin: Centre for Effective Services; 2012.

16. Hardee K, Ashford L, Rottach E, Jolivet. The Policy Dimensions of Scaling Up Health Initiatives. 2012:30.

17. Kohl R. Integrating Scaling Up Into Evaluations. 2014:22.

18. Mangham LJ, Hanson K. Scaling up in international health: What are the key issues? Health Policy and Planning. 2010;25(2):85-96. doi:10.1093/h eapol/czp066

19. Hunter DJ, Killoran A. NHS Health Development Agency. Tackling Health Inequalities: Turning Policy into Practice? London: NHS Health Development Agency; 2004.

20. Yamey G. What are the barriers to scaling up health interventions in low and middle income countries? A qualitative study of academic leaders in implementation science. Globalization and Health. 2012;8(1):11. doi:10.1186/1744-8603-8-11

21. Weiss $\mathrm{CH}$. Nothing as Practical as Good Theory: Exploring Theory-Based Evaluation for Comprehensive Community Initiatives for Children and Families. 1994.

22. Fusheini A, Eyles J. Achieving universal health coverage in South Africa through a district health system approach: Conflicting ideologies of health care provision. BMC Health Serv Res. 2016;16(1). do $\mathrm{i}: 10.1186 / \mathrm{s} 12913-016-1797-4$

23. Press Academia. Definition of Case Study. PressAcademia. 2018. https://www.pressacademia.or g/definition-of-case-study. Accessed March 8, 2019. 
24. Forero R, Nahidi S, De Costa J, et al. Application of four-dimension criteria to assess rigour of qualitative research in emergency medicine. $B M C$ Health Serv Res. 2018;18(1). doi:10.1186/s12913-01 8-2915-2

25. Saunders B, Sim J, Kingstone T, et al. Saturation in qualitative research: Exploring its conceptualization and operationalization. Qual Quant. 2018;52(4):1893-1907. doi:10.1007/s11135-017-057 $\underline{4-8}$

26. Kirton J, Kickbusch I. Delivering Universal Health Coverage 2030. 2019.

27. Bressers JTA. From public administration to policy networks: Contextual interaction analysis. Rediscovering Public Law Public Adm Comp Policy Anal Tribute Peter Knoepfel . 2009:123-142.

28. Coovadia H, Jewkes R, Barron P, Sanders D, McIntyre D. The health and health system of South Africa: Historical roots of current public health challenges. The Lancet. 2009;374(9692):817-834. do $\mathrm{i}: 10.1016 / \mathrm{s} 0140-6736(09) 60951-\mathrm{x}$

29. Nthabiseng Mohlakoana. Energy Policy A Dynamic Actor Interaction Nthabiseng Mohlakoana Implementing the South African Free Basic Alternative Energy Policy A Dynamic Actor Interaction. 2014.
30. Lipsky M. Street-Level Bureaucracy: Dilemmas of the Individual in Public Services. Michigan Law Review. 1981;79(4):811. doi:10.2307/1288305

31. Bressers H. Implementing Sustainable Development: How to Know What Works, Where, When and How. 2004;Cheltenham:284-318.

32. Kotzebue JR. Spatial misfits in multilevel governance: Impacts on the small island state of Malta. 2007.

33. Gautier L, Ridde V. Health financing policies in Sub-Saharan Africa: government ownership or donors' influence? A scoping review of policymaking processes. glob health res policy. 2017;2(1). doi:10.11 86/s41256-017-0043-X

34. Hudson B, Hunter D, Peckham S. Policy failure and the policy-implementation gap: Can policy support programs help? Policy Design and Practice. 2019;2(1):1-14. doi:10.1080/25741292.2018.1540378

35. Sabatier PA. Top-down and bottom-up approaches to implementation research: A critical analysis and suggested synthesis. J Public Policy. 1986;1:21-48. do $\mathrm{i}: 10.1017 / \mathrm{S} 0143814 \mathrm{X} 00003846$

36. Anderson N. Top-Down or Bottom-Up Approaches to Successful Change 2017. http://www.tbointl.com/bl og/top-down-or-bottom-up-approaches-to-successfu l-change. Accessed January 2, 2019. 